\title{
Note
}

[Agr. Biol. Chem., Vol. 33, No. 6, p. 959 961, 1969]

\section{Flavones in Green Tea}

\section{Part II. Identification of Isovitexin and Saponarin}

\author{
By Yutaka Sakamoto \\ Tea Research Station, Ministry of Agriculture and Forestry, \\ Kanaya, Shizuoka \\ Received September 26, 1968
}

In the previous paper, ${ }^{11}$ the author reported that nineteen flavones were newly found in green tea infusion. One of them, pigment 11, was identical with vitexin and pigment 1 seemed to be isovitexin (saponaretin) on comparison of its UV spectrum and $R f$ values with those of authentic preparation.

As pigment 1 could not be crystallized by repeated crystallization procedures, it was finally freeze-dried. The melting point (212 $214^{\circ} \mathrm{C}$ ) remained undepressed on admixture with an authentic sample of isovitexin* (measured by a micro hot stage). The IR spectrum was superimposable. (Fig. 1).

The occurrence of saponarin (vitexin-7glucoside) was not indicated in the previous paper because it could not be obtained from $2 \mathrm{~kg}$ of green tea. However a large-scale isolation procedure made it possible to prepare a relatively large amount of saponarin from

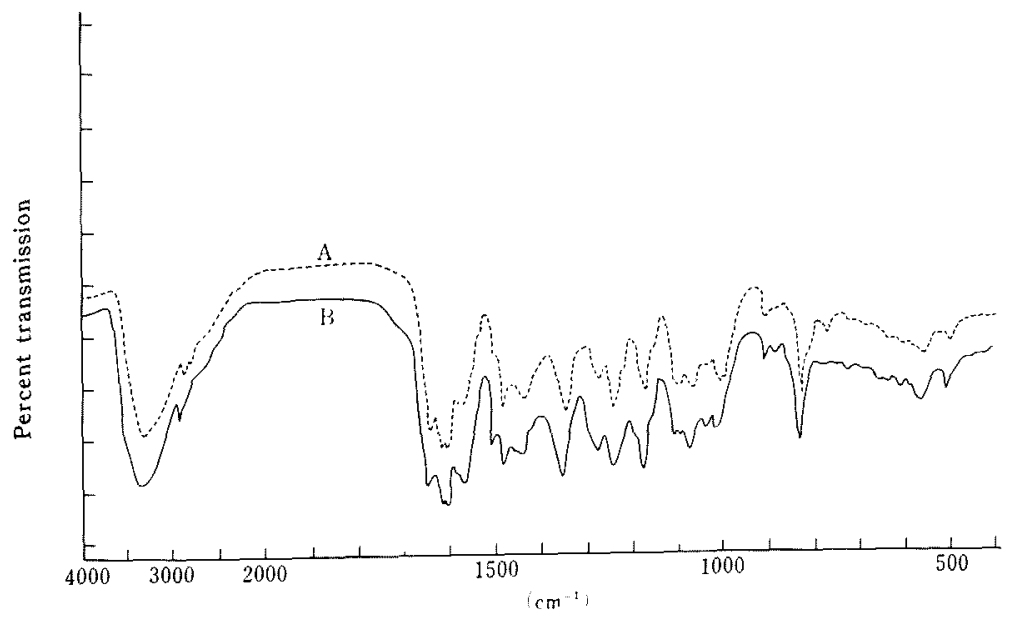

FIG. 1. IR Spectra of Authentic Isovitexin (A) and the One Isolated from Green Tea (B), (KBr disc).

1) Y. Sakamoto, Agr. Biol. Chem., 31, 1029 (1967).

* The author expresses his thanks to Dr. R.M. Horowitz (Agr. Res. Serv. U.S. Dept. of Agr., Calif. U.S.A.) for a gift of an authentic sample of isovitexin. 
Table I. Paper Chromatographic Data of Saponarin Isolated from Green Tea

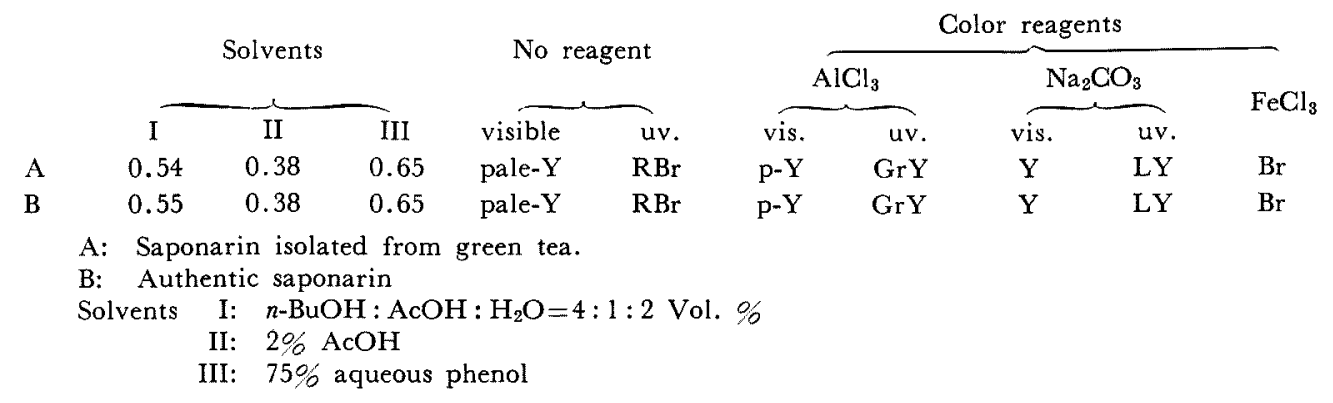

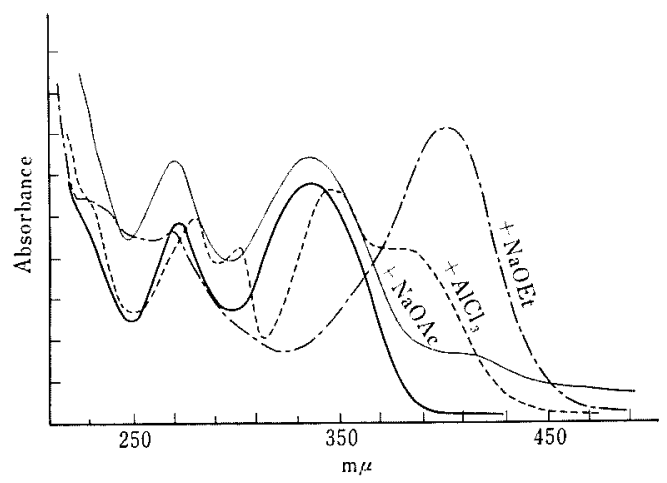

FIG. 2. UV Spectra of Isolated Saponarin (13 mg/ liter) (in $\mathrm{EtOH}$ )
$20 \mathrm{~kg}$ of green tea.

The isolation method of pigments fror green tea infusion was described in the prt vious paper. ${ }^{11} \quad$ By means of nylon powder an then silica gel-water saturated $n$-butanol colum chromatographies, the fractions containin saponarin only were separated from the othe pigments. Crude saponarin was obtained c brownish yellow sandy powder. Recrystallizi tion from a large volume of boiling ethanc gave about $150 \mathrm{mg}$ of pure. saponarin.

The isolated saponarin was a pale yellor substance and melted at $229^{\circ} \mathrm{C}$ (with a micr hot stage). When it was dried at about $135^{\circ}$ (xylol bath) for $2.5 \mathrm{hr}$ over phosphorus per

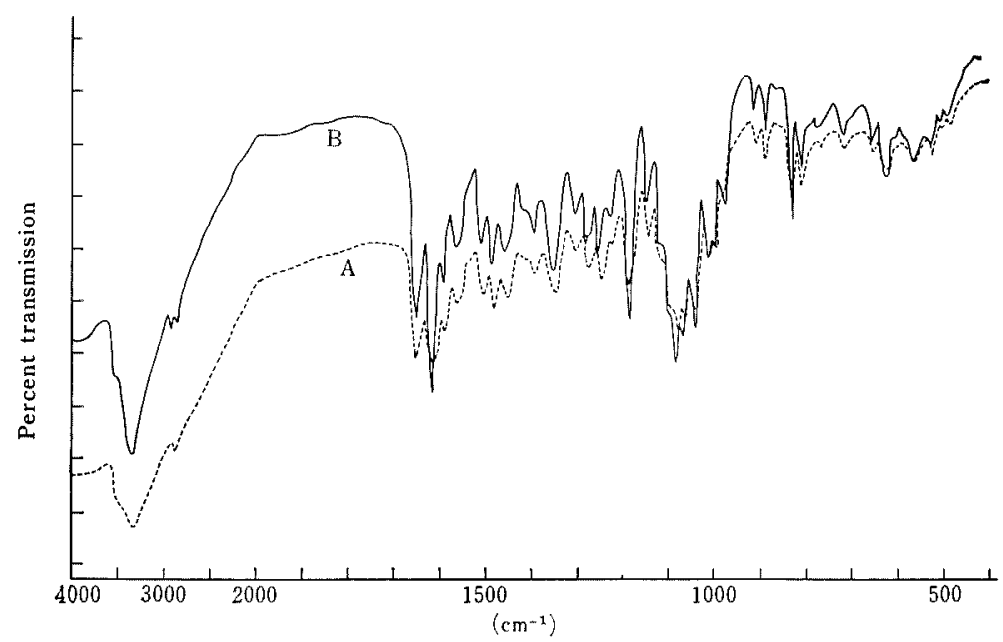

FIG. 3. IR Spectra of Authentic Saponarin (A) and the One Isolated from Green Tea (B), (KBr disc). 
toxide in vacuo, $24.89 \mathrm{mg}$ of the sample lost $1.07 \mathrm{mg}$ of the weight which corresponds to 1.5 moles of $\mathrm{H}_{2} \mathrm{O}(4.25 \%)$.

Anal. Found*: C, 50.86; H, 5.62. Calcd. for $\mathrm{C}_{27} \mathrm{H}_{32} \mathrm{O}_{16} \cdot 1 \frac{1}{2} \mathrm{H}_{2} \mathrm{O} \quad\left(\mathrm{H}_{2} \mathrm{O}=4.22 \%\right): \quad \mathrm{C}$, $50.70 ; \mathrm{H}, 5.48 \%$. Moreover, it was identical with authentic saponarin ${ }^{* *}$ on comparison of ther $R f$ values, UV and IR spectra, $\mathrm{mp}$, and color reactions. $R f$ values of saponarin are shown in Table I. The sample showed absorption maxima at $272 \mathrm{~m} \mu(\log \varepsilon=4.38)$ and 335 $\mathrm{m} \mu \quad(\log \varepsilon=4.44)$, and the absorption spectral data on aluminum chloride complex-, sodium acetate-, and sodium ethylate shift coincident with those of the authentic preparation as shown in Fig. 2.***

* Elementary analysis was carried out by the Lab. of Elem. Anal., Shizuoka Univ. of Pharm.

** The authentic saponarin was given by Dr. N. Morita, Prof. of Toyama Univ., to whom the auther wishes to express his thanks.

*** UV spectra were examined with a Beckman DB spectrophotometer with a potentiometic recorder.
The IR spectra of the sample and authentic saponarin were also completely superimposable as shown in Fig. 3.*

In green tea infusion, the content of saponarin was generally so small $(150 \mathrm{mg} / 20 \mathrm{~kg})$ that the spot was supposed not to be detected on the paper chromatogram. However, further paper chromatographic studies revealed that the saponarin content varied depending on the source of green tea, for example, varieties, the places of production and so forth. Therefore, the spot of saponarin was detected on the two dimentional paper chromatograms if the samples which had relatively high contents of it.

* IR spectra were recorded with an Infrared spectrophotometer, IR-G, Japan Spectroscopic Co. 